\title{
MEDIAL PREFRONTAL CORTEX AND COGNITIVE REGULATION
}

\author{
Takashi NAKAO ${ }^{1,2)}$, Tomohiro TAKEZAWA ${ }^{3)}$, Makoto MIYATANI ${ }^{4)}$, and Hideki OHIRA ${ }^{2)}$ \\ 1) Japan Society for the Promotion of Science (JSPS), ${ }^{2)}$ Nagoya University, Japan \\ 3) Research Institute, National Rehabilitation Center for Persons with Disabilities, Japan \\ 4) Hiroshima University, Japan
}

\begin{abstract}
Medial prefrontal cortex (MPFC) activation has been observed in studies of many types related to emotion regulation, self and familiar other-knowledge, mentalizing, morality, reward, and uncertainty. Furthermore, the anterior cingulate cortex (ACC) and the lateral prefrontal cortex (LPFC), which have reciprocal connections with MPFC, are considered necessary for cognitive regulation. Based on these findings, Nakao, Takezawa, and Miyatani (2006) proposed an integrative explanation for MPFC function: MPFC has a function of representing a benchmark that reduces conflict among many possible answers by biasing either choice of behavior. In this article, we review studies related to MPFC function and the benchmark hypothesis with recent new findings. Additionally, we discuss emotion regulation, which was not described in Nakao et al. (2006), in relation to the benchmark hypothesis.
\end{abstract}

Key words: emotion, self, theory of mind, conflict, social decision making

Numerous social cognitive neuroscience studies have been conducted in recent years. Cognitive tasks of many types, such as controlling one's own emotions, thinking about one's own personal traits, inferring another person's feelings, making moral judgments, and learning of reward contingencies under uncertainty, have all been used to induce activation of the medial prefrontal cortex (MPFC; Brodmann area (BA) 8, 9, 10; see Fig. 1). The variety of cognitive tasks begs the question: what is the function of the MPFC? Nakao, Takezawa, and Miyatani (2006) proposed a possible integrative explanation for the MPFC function. Herein, in light of recent findings, we review studies of the MPFC function and the benchmark hypothesis. Additionally, we discuss emotion regulation, which was not described in Nakao et al. (2006), in relation to the benchmark hypothesis. This review is presented as three sections describing (1) medial prefrontal cortex studies, (2) functions of prefrontal regions adjacent to the MPFC, and (3) the benchmark hypothesis.

\section{Medial Prefrontal Cortex Studies}

The MPFC in the human brain is larger relative to the rest of the brain than it is in other species (Semendeferi, Armstrong, Schleicher, Zilles, \& Van Hoesen, 2001). The

This work was supported by a Grant-in-Aid for JSPS Fellows (No. 20•821) and by a Grant-in-Aid for Scientific Research (B) (No. 20330148) from the Japan Society for the Promotion of Science.

Correspondence concerning this article should be addressed to: Takashi Nakao, Ph.D. Nagoya University, Graduate School of Environmental Studies, Furo-cho, Chikusa-ku, Nagoya, 464-8601 Japan (E-mail: takana818@lit.nagoya-u.ac.jp). 


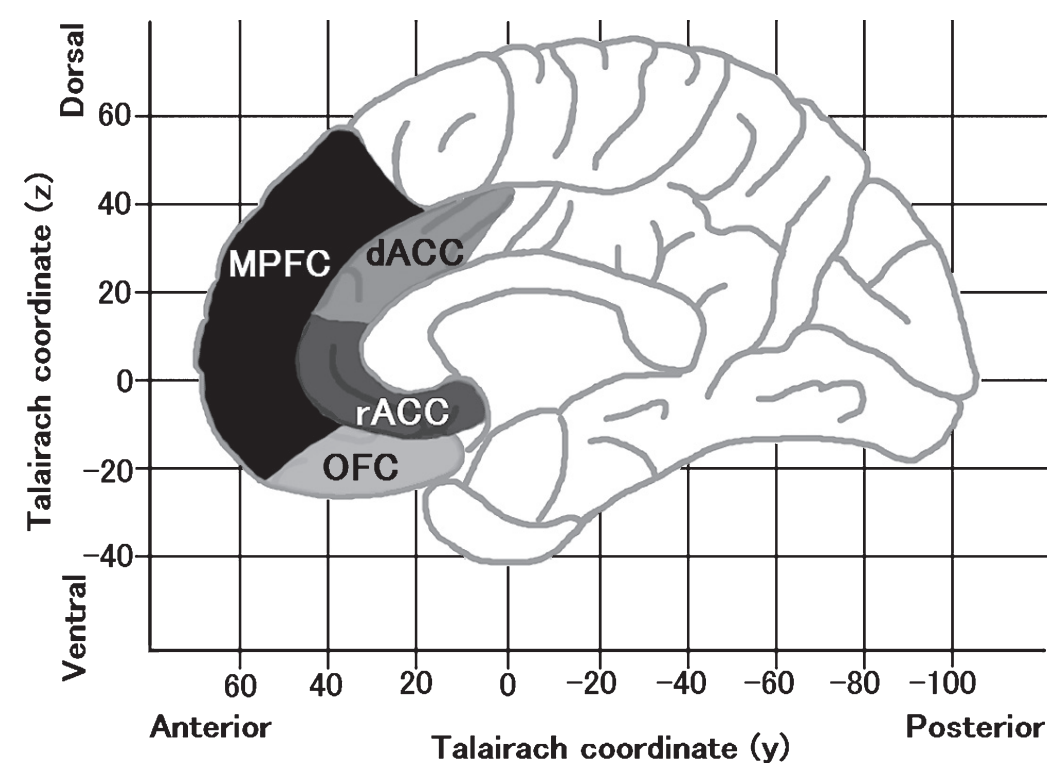

Fig. 1. Schematic illustration of medial frontal regions: MPFC, medial prefrontal cortex; dACC, dorsal anterior cingulate cortex; rACC, rostral-ventral anterior cingulate cortex; OFC, orbit-frontal cortex.

MPFC has connections with the neighboring prefrontal areas, lateral prefrontal cortex (LPFC), anterior cingulate cortex (ACC), and orbito-frontal cortex (OFC) (Fig. 1). The MPFC is also reciprocally connected with several limbic structures: its strongest limbic connections are with the amygdala. The dorsal temporal pole, rostral part of the superior temporal gyrus, and dorsal bank of the superior temporal sulcus also have connections with the MPFC (Ongur \& Price, 2000; Petrides \& Pandya, 2007; Price, 2007).

In this section, we present a review of previous studies that have investigated MPFC functions related to emotion regulation, knowledge about self and a familiar other person, mentalizing, morality, and learning of the reward contingencies under uncertainty. Fig. 2 shows mapping of MPFC activations found in neuroimaging studies of each cognitive function cited in the following.

\section{Emotion Regulation}

Recent neuroimaging reports have described that the MPFC is activated during emotion regulation, as through reappraisal, which is defined as the cognitive transformation of emotional experience (Banks, Eddy, Angstadt, Nathan, \& Phan, 2007; Ochsner, Bunge, Gross, \& Gabrieli, 2002; Ochsner, Ray et al., 2004; Urry et al., 2006; for reviews, see Haensel \& von Kaenel, 2008; Ochsner \& Gross, 2008). Ochsner et al. (2002) examined the neural systems used to reappraise highly negative scenes using functional magnetic resonance imaging (fMRI). In the reappraisal condition, participants were asked to interpret photographs so that they no longer felt negative in response to them. In the control condition, participants were asked to let themselves respond emotionally to each 


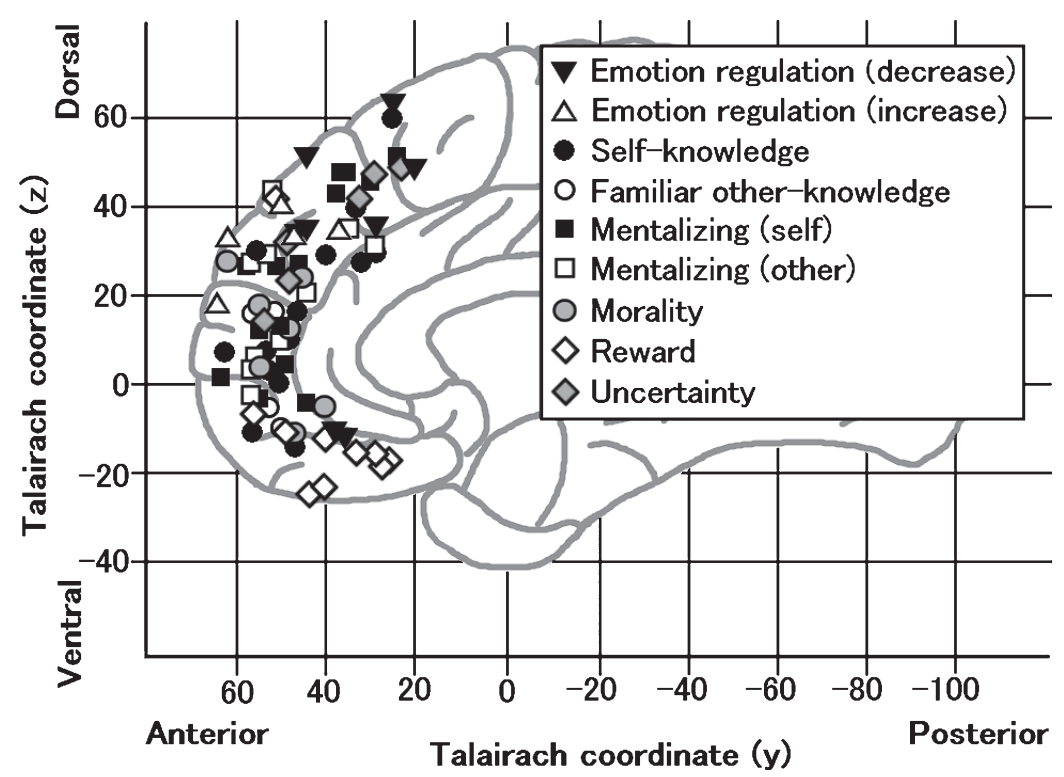

Fig. 2. Mapping of the medial prefrontal cortex (MPFC) activations found in neuroimaging studies cited in this article.

photograph according to their feelings without trying to alter them. Results showed that neural correlates of reappraisal increased activation of the MPFC and the LPFC, and decreased activation of the amygdala and medial region of OFC. Ochsner, Ray et al. (2004) showed that not only regulation to decrease negative emotion but also regulation to increase negative emotion activated the MPFC, but the sub-regions were different: as portrayed in Fig. 2, regulation to increase negative emotion recruited relatively inferior regions of the MPFC compared with regulation to decrease. It has also been reported that depressive disorders impair the MPFC's regulatory function on amygdala activity (Johnstone, van Reekum, Urry, Kalin, \& Davidson, 2007). Although results of these studies suggest that the MPFC functions to regulate emotion, the functional details (e.g., the process reflected in the MPFC activity and the reason of the activation of MPFC) are not readily apparent.

\section{Self-knowledge and Familiar Other-knowledge}

Self-knowledge is the semantic knowledge of one's own personal traits and abilities. Several neuroimaging studies of self-knowledge have found consistently that the MPFC is engaged selectively during self-knowledge reference (e.g., Does the word describe you?kind) (D'Argembeau et al., 2007; Fossati et al., 2003; Heatherton et al., 2006; Johnson et al., 2002; Kelley et al., 2002; Kjaer, Nowak, \& Lou, 2002; Lieberman, Jarcho, \& Satpute, 2004; Northoff \& Bermpohl, 2004; Northoff et al., 2006; Schmitz, Rowley, Kawahara, \& Johnson, 2006). Fig. 2 shows that activation of entire regions of the MPFC has been found in neuroimaging studies of self-knowledge. For example, Kelley et al. (2002) 
investigated cerebral activity while participants processed trait adjectives under the following three conditions: self-knowledge reference, unfamiliar other-knowledge reference (participant judged whether a trait describes U.S. President or not), and case judgment. They found that a separate region of the MPFC was engaged selectively during self-knowledge reference.

However, MPFC activation has been observed also when a participant made a judgment about a familiar other person (Nakao, Miyatani et al., in press; Ochsner et al., 2005; Seger, Stone, \& Keenan, 2004; Vanderwal, Hunyadi, Grupe, Connors, \& Schultz, 2008). For example, in Seger et al. (2004), a friend who was known by a participant was used as an other-knowledge reference. Consequently, MPFC activation was observed not only during self-knowledge reference but also during familiar other-knowledge reference. During self-knowledge reference and other-knowledge reference, posterior cingulate (BA 23,31 ) and precuneus (BA 7) activities were observed frequently.

\section{Mentalizing}

In fact, MPFC activation has been observed not only when participants refer knowledge about self and familiar other person, but also when they refer a mental state of the self (Gusnard, Akbudak, Shulman, \& Raichle, 2001; Lane, Fink, Chau, \& Dolan, 1997; Nakao, Miyatani et al., in press; Northoff et al., 2006; Paulus \& Frank, 2003; Zysset, Huber, Ferstl, \& von Cramon, 2002; Zysset, Huber, Samson, Ferstl, \& von Cramon, 2003) and other person (Brunet, Sarfati, Hardy-Bayle, \& Decety, 2000; Calder et al., 2002; Fletcher et al., 1995; Gallagher et al., 2000; Iacoboni et al., 2004; Mitchell, Banaji, \& Macrae, 2005; Mitchell, Macrae, \& Banaji, 2006; Saxe, Moran, Scholz, \& Gabrieli, 2006). The ability to attribute mental states such as emotions, thoughts, beliefs, and intentions to people is designated as mentalizing (particularly, the ability to mentalize an other person's mental state is called theory of mind; for additional review, see Amodio \& Frith, 2006; Frith \& Frith, 1999, 2006; Gallagher \& Firth, 2003; Nomura, 2004). Fig. 2 shows that a broad area of MPFC activation has been found in neuroimaging studies of mentalizing. Nakao, Miyatani et al. (in press) reported that the sub-region of MPFC was commonly activated by self-knowledge reference and self-monitoring. In addition, Saxe et al. (2006) reported that MPFC sub-regions recruited by the self-knowledge reference and theory of mind task - a false-belief task requiring the ability to reason about other persons' mental states - partly overlap in individuals.

Ochsner, Knierim et al. (2004) compared brain regions involved in judging one's own emotional state to those used for judging another individual's emotional state. Participants were instructed to evaluate either their emotional response to each of several photographs, the emotional state of the central figure in each photograph, or (in a baseline condition) whether the photograph was taken indoors or outdoors. Results showed that MPFC was commonly activated during self and other evaluation of emotion. Vogeley et al. (2001) also reported that both mentalizing of self and another person activated MPFC using narrative stimuli. Castelli, Happe, Frith, and Frith (2000) summarized that the MPFC is thought to support the ability of mentalizing in general. The superior temporal region (BA 22, 39) and the temporal pole (BA 21, 38) have often been reported as activated areas during mentalizing. 


\section{Morality}

Morality has also been thought to relate to the MPFC function (see Fig.2; Greene, Nystrom, Engell, Darley, \& Cohen, 2004; Greene, Sommerville, Nystrom, Darley, \& Cohen, 2001; Heekeren, Wartenburger, Schmidt, Schwintowski, \& Villringer, 2003; Moll, de Oliveira-Souza, Bramati, \& Grafman, 2002; Takahashi et al., 2004). For example, Moll, de Oliveira-Souza, Eslinger et al. (2002) presented pictures with moral content (e.g., physical assaults, poor children abandoned in the streets, war scenes), and others without moral content (e.g., body lesions, dangerous animals, body products). A picture with moral content produced increased activity in the MPFC relative to when participants were shown a picture without moral content. Ciaramelli, Muccioli, Ladavas, and di Pellegrino (2007) reported that patients with lesions in the ventral region of the MPFC were inclined to judge personal moral violations as acceptable. Based on such findings, the MPFC has been thought to play an important role for morality. In neuroimaging studies, the superior temporal gyrus (BA21, 22, 38, 39) was also frequently activated during moral judgment (for additional reviews, see Greene \& Haidt, 2002; Young \& Koenigs, 2007).

\section{Reward and Uncertainty}

The ventral MPFC and the medial $\mathrm{OFC}^{1}$ have been implicated in the generation of an abstract representation of the rewarding value of a stimulus, which is learned from reinforcement contingencies (O'Doherty, Critchley, Deichmann, \& Dolan, 2003; Rolls, 2000, 2004). Results of experiments on monkeys showed that neurons within the ventral MPFC and medial OFC activate during learning of reinforcement contingency (Hikosaka \& Watanabe, 2000, 2004; Matsumoto, Suzuki, \& Tanaka, 2003; Matsumoto \& Tanaka, 2004a, 2004b). Rolls, Hornak, Wade, and McGrath (1994) reported that human patients with damage to the ventral part of the frontal lobes, including damage to the ventral MPFC, were severely impaired in reversal learning: they continued to make responses to a previously rewarded but not presently rewarded stimulus. Neuroimaging studies with the normal participants have revealed that the ventral MPFC responds to the reward magnitude (Elliott, Newman, Longe, \& Deakin, 2003; Ernst et al., 2004; O'Doherty, Kringelbach, Rolls, Hornak, \& Andrews, 2001; O'Doherty et al., 2003; Rogers et al., 2004; Small, Zatorre, Dagher, Evans, \& Jones-Gotman, 2001; Xue, Lu, Levin, Weller, Li, \& Bechara, in press).

In situations where the reinforcement contingency was uncertain, such as gambling tasks $^{2}$, the dorsal MPFC is known to be engaged in addition to the ventral MPFC (Bechara, Damasio, Damasio, \& Lee, 1999; Fukui, Murai, Fukuyama, Hayashi, \&

\footnotetext{
${ }^{1}$ Price (2007) classified the MPFC and medial OFC as the same functional network (medial network) based on intrinsic and extrinsic connections.

${ }^{2}$ In the gambling task, participants were asked to choose between decks of cards yielding a high immediate gain but a larger future loss (long-term net loss), and decks yielding a lower immediate gain but a smaller future loss (long-term net gain). The participants' goal of the task is to maximize the profit earned on a loan of play money. Bechara et al. (Bechara, Damasio, Damasio, \& Anderson, 1994; Bechara et al., 1999; Bechara, Tranel, Damasio, \& Damasio, 1996) reported that patients with damage to the ventral MPFC showed a deficit in the performance of a gambling task: As the trial progressed, although normal participants chose the decks providing a long-term gain, the patients chose disadvantageously (long-term net loss).
} 
Hanakawa, 2005). Results of neuroimaging studies have shown that the uncertainty of an outcome modulates the degree of dorsal MPFC response (Hsu, Bhatt, Adolphs, Tranel, \& Camerer, 2005; Volz, Schubotz, \& von Cramon, 2003, 2004; Xue et al., in press). For example, Volz, et al. (2003) examined brain activity during participants' prediction of which of the two concurrently presented stimuli would win in a virtual competition game. Uncertainty was manipulated by varying the probabilities of winning. Results revealed that the dorsal MPFC is increasingly activated by increasing uncertainty. The dorsal MPFC is thought to be related to the fear or anxiety of uncertainty, which leads to riskavoiding behavior to (Xue et al., in press) or searching for additional information from the environment (Hsu et al., 2005). In these neuroimaging studies, ACC activations are also frequently observed during uncertain decision-making.

\section{Functions of Prefrontal Regions Adjacent to MPfC}

Why is the MPFC activated by various tasks related to emotion regulation, selfknowledge, familiar other-knowledge, mentalizing, morality, reward, and uncertainty? Nakao et al. (2006) proposed an integrative explanation of the MPFC function based on the relation to the function of the neighboring prefrontal regions, anterior cingulate cortex (ACC) and lateral prefrontal cortex (LPFC). The MPFC has connections with these neighboring prefrontal areas (Ongur \& Price, 2000; Petrides \& Pandya, 2007; Price, 2007). In this section, we review ACC and LPFC functions briefly.

\section{Anterior Cingulate Cortex}

The ACC, which is located in a transition zone between the limbic and frontal cortex, comprises rostral-ventral (BA24, 25, 32) and dorsal portions (BA24', 32') (see Fig. 1; Ridderinkhof, van den Wildenberg, Segalowitz, \& Carter, 2004). The rostral-ventral ACC is considered the affective division connected to the amygdala, whereas the dorsal ACC is considered the cognitive division, which has a function of cognitive regulation and which maintains strong reciprocal interconnections with LPFC (BA 46/9).

One important function of the dorsal ACC is response conflict monitoring ${ }^{3}$. Response conflict arises when incompatible response tendencies are simultaneously active, and the degree of response conflict is thought to be evaluated by the dorsal ACC (Botvinick, Braver, Barch, Carter, \& Cohen, 2001). The function of response conflict monitoring has been investigated using tasks for which the error response is activated easily, as by a Stroop task (Stroop, 1935). In the Stroop task, when naming the ink color of incongruent compound stimuli (e.g., the word red printed in green ink), an incompatible response can be activated. The response conflict is evident in behavioral measures of reaction times and error rates, with incongruent stimuli leading to longer reaction times

\footnotetext{
${ }^{3}$ The dorsal ACC might be important not only for conflict monitoring but also for monitoring of errors and unfavorable outcomes (Ridderinkhof, Ullsperger, Crone, \& Nieuwenhuis, 2004; Sato \& Ohira, 2001). In this article, we mainly describe the conflict monitoring function because we discuss the hypothesis related to behavior selection in conflict-ridden situations where two or more possible answers exist
} 
and higher error rates (MacLeod, 1991). Numerous neuroimaging studies have documented that greater dorsal ACC activation is observed when the incompatible response tendencies are activated (Egner \& Hirsch, 2005a; MacDonald, Cohen, Stenger, \& Carter, 2000; Milham, Banich, \& Barad, 2003). Greene et al. (2004) reported that conflict during moral judgment is also reflected in dorsal ACC activation. It is thought that upon the detection of the conflict, the dorsal ACC signals the LPFC that the level of cognitive regulation must be increased (Botvinick et al., 2001).

\section{Lateral Prefrontal Cortex}

The LPFC is conceptualized as having two architectonically distinct regions: the dorsal (BA8, 9, 46) and ventral (BA12, 44, 45, 47). The dorsal LPFC receives inputs largely from areas in the MPFC, whereas the ventral LPFC receives afferents mostly from areas in the OFC (Barbas \& Pandya, 1989; Tanji \& Hoshi, 2008). Although some functional differences between these two regions have been suggested (Goldman-Rakic, 1988; Hoshi \& Tanji, 2004; Petrides, 1995), these regions work together in broad aspects of cognitive regulation through the intrinsic connections between the dorsal and ventral networks. For example, the LPFC has functions for representing task-relevant information (task requirements and behavior choice; Hoshi, Shima, \& Tanji, 1998, 2000), attentional function to code information of specific relevance to current behavior (Durston et al., 2003; Egner \& Hirsch, 2005b; Luks, Simpson, Feiwell, \& Miller, 2002), and an inhibition function against prepotent or erroneous responses (Aron, Robbins, \& Poldrack, 2004; Konishi et al., 1999; for additional review see Tanji \& Hoshi, 2008).

Cognitive regulation within the LPFC is thought to be recruited and carried out to reduce conflict when a conflict is detected in the dorsal ACC (Botvinick et al., 2001). Using the Stroop color-naming task, Kerns et al. (2004) demonstrated that dorsal ACC conflict-related activity accurately predicted both greater LPFC activity and adjustments in behavior on the next trial: the dorsal ACC, which is inferred as a monitor of conflict, and the LPFC, a controller of behavior, mutually interact to regulate behavior.

\section{BENCHMARK HYPOTHESIS}

As described above, the MPFC is reportedly activated during cognitive tasks of many types related to emotion regulation, self-knowledge, familiar other-knowledge, mentalizing, morality, rewards, and uncertainty. Consequently, the function of the MPFC remains unclear. Meanwhile, dorsal ACC and LPFC have a function for monitoring and regulation of conflict. However, studies of cognitive regulation have been limited to tasks which have a correct answer, such as the Stroop task; little attention has been devoted to cognitive regulation in a situation where two or more possible answers exist. Our real-life social behavior selection (e.g., occupation choice or interpersonal communication) often includes situations with many possible answers and without apparent feedbacks.

Nakao et al. (2006) proposed the benchmark hypothesis to surmount these limitations. By this hypothesis, they assert that the MPFC also has a function of cognitive 


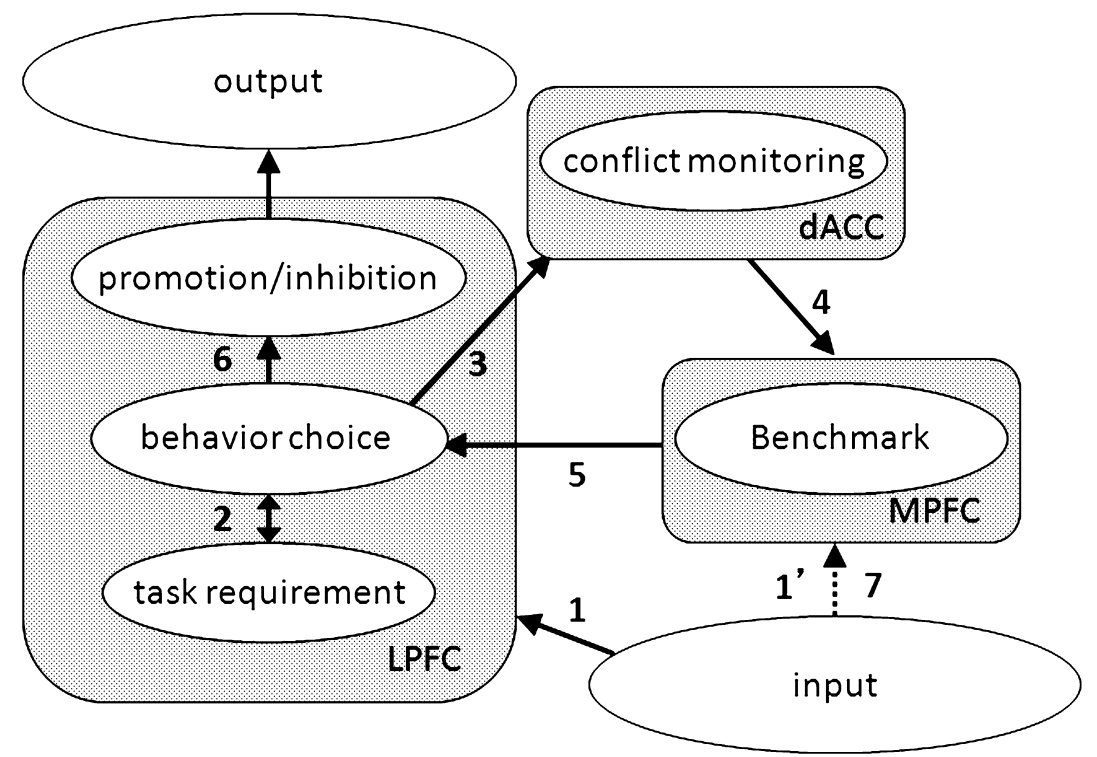

Fig. 3. Relation among medial prefrontal cortex (MPFC), dorsal anterior cingulate cortex (dACC), and lateral prefrontal cortex (LPFC) assumed in the benchmark hypothesis (Nakao et al., 2006). During behavior selection, after receiving input (1), the task requirement and behavior choices are represented in the LPFC (2). Where two or more possible answers exist, incompatible response tendencies are simultaneously active, and conflict is evaluated in dACC (3). Then, the benchmark represented in the MPFC is activated (4), biasing either choice of behavior (5). Within the LPFC, the most-biased choice is promoted to output. The other behavior choices are inhibited (6). After behavior selection, learning based on the conflict occurs: Connection between the most-activated benchmark and input is enhanced (7). The same benchmark tends to be used under similar circumstances (1').

regulation: the MPFC is a region that is responsible for representing benchmarks used as behavior selection criteria. A benchmark refers to information that reduces conflict by biasing either choice of behavior in a situation where two or more possible answers exist. In such situations (e.g., occupational choice or behavior selection in interpersonal communication), conflict would occur because incompatible response tendencies could be active simultaneously. The MPFC representations (e.g., self-knowledge, familiar otherknowledge, self or other person's mental state, morality, rewards, and anxiety/fear of uncertainty) act as a benchmark that biases either choice of behavior to reduce conflict arising when confronting many possible answers. Based on the bias from the MPFC, the LPFC controls behavior and conflict is reduced (Fig. 3).

As presented in Fig. 2, medial OFC activities were related to the reward, whereas the MPFC was related not only to rewards but also to socio-cognitive tasks of various types. Consequently, it is likely that although the MPFC has a function to represent benchmarks of various types, the medial OFC function is relatively restricted to represent a welldefined value that has been acquired through the feedback.

The MPFC representation, which acts as a benchmark, is thought to vary according 
to the situation. For example, personal aptitudes (self-knowledge) would function as a benchmark when people choose suitable occupations for themselves. In contrast, knowledge about the child's traits and abilities (other-knowledge) would function as a benchmark when parents think about their child's future.

This benchmark concept includes the following three hypotheses. (1) The more frequently the information is used as a benchmark, the more the information increases MPFC activities. (2) Information represented by the MPFC acts as a benchmark; it reduces conflict at the time of behavior selection in a situation where two or more possible answers exist. (3) The same benchmark tends to be used under similar situations that occur later when a certain behavior is selected after the initial conflict has occurred. In the following, we explain the first and second hypotheses, which have collateral evidence, and present discussion of the relation between emotion regulation and the benchmark hypothesis.

\section{Function of Representing Benchmark}

The benchmark hypothesis is an assertion that the more frequently the information is used as a benchmark, the more the information increases MPFC activities: information that has been used frequently as a benchmark (e.g. self-knowledge) is processed in those tasks which induce more MPFC activation (e.g. self-knowledge reference task). It is thought that MPFC activities have been found during self-knowledge reference, familiar other-knowledge reference, mentalizing, moral judgment, and reinforcement learning under uncertainty because these tasks include processing of information that is frequently used as a benchmark (i.e., self-knowledge, familiar other-knowledge, self- and othermental states, moral knowledge, representations of reward, and anxiety/fear of uncertainty).

A difference of MPFC activity would arise between the benchmarks when the frequencies of information used as benchmarks differ. Lieberman et al. (2004) reported that more MPFC activity is found when participants conduct self-knowledge reference in the high-experience domain (e.g. when a soccer player judges whether "team player" is self-descriptive) than in the low-experience domain (e.g. when a soccer player judges whether "actor" is self-descriptive).

As we have explained, some reports have described that self-knowledge reference activates the MPFC more than other-knowledge references (Kelley et al., 2002), other studies have reported that other-knowledge references also activate the MPFC as well as self-knowledge (Seger et al., 2004). A possible explanation of that apparent contradiction is the frequency of use of other-knowledge as a benchmark. Knowledge about other people who have personally interacted with participants (as in Seger et al.) might be processed within the MPFC because such information had been used as a benchmark for previous behavior selection in interpersonal communication. However, knowledge about famous people (as in Kelley et al.) might not be processed within the MPFC because such information has not been useful for individual behavior selection.

The difference of use-frequency of knowledge for daily behavior selection yields differences of MPFC activities. Krueger, Moll, Zahn, Heinecke, and Grafman (2007) 
examined brain activity as participants judged whether event sequences from high-, moderate-, and low-frequency daily life activities were ordered correctly. Their results showed that different MPFC subregions were activated depending on frequency.

Interestingly, beliefs that would bias behavior affect the MPFC activity. Han, Mao, $\mathrm{Gu}, \mathrm{Zhu}, \mathrm{Ge}$, and Ma (2008) reported that self-knowledge reference induced increased activity in the ventral MPFC for non-religious participants but in the dorsal MPFC for Christian participants. Moreover, the dorsal MPFC activity was positively correlated with the rating scores of the judged importance of Jesus. Harris, Sheth, and Cohen (2008) reported that the MPFC is activated more when participants conducted belief judgment about moral statements than when they conducted disbelief judgment.

\section{Function of Conflict Reduction}

By assuming that information represented by the MPFC acts as a benchmark, the function conducted in dorsal ACC and LPFC is applicable to the situation in which many possible answers exist, such as social behavior selection. As described above, the LPFC activation represents task-relevant information (task requirements and behavior choice). The degree of conflict is evaluated within the dorsal ACC and cognitive regulation (e.g. inhibit inappropriate behavior) to reduce conflict is conducted in the LPFC if many choices that activate incompatible response tendencies are represented in the LPFC. However, in a situation where one possible correct answer is not already determined by the external environment, the LPFC cannot regulate behavior unless the response which should be outputted is determined internally. In such cases, the benchmark represented in the MPFC is activated, and the response which should be chosen is determined (Fig. 3).

Some reports have described evidence implying that the MPFC activity affects behavior selection. Lotze, Veit, Anders, and Birbaumer (2007) investigated such brain activity during retaliation: participants were provoked by increasingly aversive stimuli and were given the opportunity to respond aggressively against their opponent by administering a stimulus as retaliation. They found that the dorsal MPFC was active when participants had to select the intensity of the retaliation stimulus. Its activity correlated with the selected stimulus strength. Xue et al. (in press) reported that participants who showed a stronger level of activation of dorsal MPFC when making a risky choice than when making a riskless choice frequently avoid risky choices. In contrast, participants who showed a higher level of activation of ventral MPFC when receiving a win than when receiving a loss frequently make risky choices.

A functional relation between the dorsal ACC and the MPFC proposed by the benchmark hypothesis is implied by results of several studies. For example, it is reported that not only the dorsal ACC, which has a function to evaluate conflict, but also the MPFC, is activated in a situation where the right answer is unclear (Harris et al., 2008; Knutson, Taylor, Kaufman, Peterson, \& Glover, 2005; Xue et al., in press). Nakao, Takezawa, Shiraishi, and Miyatani (in press) showed that activation of self-knowledge reduces conflict during an occupational choice task (e.g., Which occupation do you think you could do better?- - dancer or chemist) which has two possible answers. Conflict was measured via conflict-related negativity (CRN), the amplitude of which reflects strength 
of conflict (Simon-Thomas \& Knight, 2005). To evaluate the effects of self-knowledge related to conflict during the occupational choice task, they used blocks of two types: one for the self-knowledge task and the occupational choice task, and another for the otherknowledge task, which requires judgment of an unfamiliar other person (e.g. Does this word describe Prime Minister Koizumi?-strict) and the occupational choice task. Consequently, the CRN amplitude during the occupational choice task was smaller in the block with self-knowledge task than in the block with the unfamiliar other-knowledge task. The results suggest that self-knowledge has a benchmark function that reduces conflict between two possible answers.

Results of some studies imply a functional relation between the MPFC and LPFC. Goel and Dolan (2003) examined brain activity as participants performed reasoning tasks (syllogisms) that are logically valid but which yield implausible conclusions (e.g. No harmful substances are natural; All poisons are natural; $\therefore$ No poisons are harmful). The activation of MPFC was found when participants formed judgments on the bases of belief compared with when they formed judgments on the bases of adequate reasoning. The reverse comparison revealed activation of the LPFC. These results suggest that representation of the MPFC (i.e. belief) might bias behavior selection conducted within the LPFC. A similar finding was also reported by Harris et al. (2008): although MPFC activities were found when participants conducted belief judgment about some statements (e.g., related to morality or religion), LPFC activity was identified when they conducted disbelief judgment.

\section{Relation between Emotion Regulation and Benchmark Hypothesis}

Although previous reports have described that MPFC is activated during emotion regulation (reappraisal), it is not readily apparent (1) what process is reflected in the MPFC activity and (2) why the MPFC is activated during reappraisal. Regarding the first question, based on the previous studies reviewed above, we can infer the process reflected in MPFC activity: it is thought that benchmarks (e.g., self-knowledge, self and other person's mental state, moral knowledge, and representation of reward) would be activated when participants try to regulate emotion by reappraisal. Previous reports have described the possibility that MPFC activity during reappraisal reflects monitoring of one's own emotional state (mentalizing) (Banks et al., 2007; Ochsner et al., 2002). However, the MPFC is thought to represent not only one's own emotional state but also the benchmarks of other types. Therefore, it is possible that benchmarks of all types can be activated during reappraisal. For example, when participants are presented a picture of grievously injured person, it is possible that they avoid negative feelings by thinking about morality, such as "It is not good to release a negative reaction about an injured person."

Secondly, why is the MPFC activated during reappraisal? It is likely that the answer is derived from the notion that both the MPFC representation and the amygdala function to bias behavior selection: although emotion often biases our behavior strongly, we do not always express emotional behavior by thinking, for example, of another person's mental state and morality. It is thought that the MPFC and amygdala mutually interact to choose one's behavior through reciprocal connections (Price, 2007). Participants would apply the 
connection between MPFC and the amygdala to decrease their own emotional response when they try to regulate emotion by reappraisal: the MPFC representation, which has an inhibitory connection with the amygdala, would be activated during reappraisal. Banks et al. (2007) reported that the strength of functional coupling between the amygdala and the MPFC predict successful emotion regulation.

It is thought that the MPFC and amygdala do not always bias different behavior choices: Some benchmarks bias behavior choice that is also biased by emotion. Therefore, the MPFC is activated not only when participants try to decrease their own emotional response but also when they try to increase their emotional response (Ochsner, Ray et al., 2004).

If we can activate adequate benchmark biasing behavior choice that is opposite the choice that is biased by emotion, we would successfully decrease the emotion; meanwhile if we were able to activate adequate benchmark biasing behavior choice that is also biased by emotion, we would successfully increase the emotion.

\section{CONCLUSIONS}

In this review, we described studies related to MPFC functions and the benchmark hypothesis with recent new findings, and discussed emotional regulation in relation to the hypothesis. Previous reports have described that MPFC activation has been observed in studies of many types related to emotion regulation, self-knowledge, familiar otherknowledge, mentalizing, morality, reward, and uncertainty. The benchmark hypothesis provides a possible integrative explanation of MPFC function: the MPFC benchmarks bias any of several behaviors in a situation where many possible answers exist. The hypothesis also helps to clarify why the MPFC is activated during emotion regulation.

It is important to study what process is involved in high-order cognitive function, such as mentalizing. However, to understand high-order cognitive function, it would also be important to study what processes require self-knowledge, familiar other-knowledge, self/other-person's mental states, and morality. In recent years, such a viewpoint has been suggested by several researchers. Lieberman and Eisenberger (2005) proposed that autobiographical memory about a past solution to conflicts, as represented in medial temporal lobes, has a function of reducing conflict. Buckner and Carroll (2006) advanced the speculative possibility that prospection (envisioning the future), episodic memory, mentalizing of other persons and navigation (simulating another view or mapping the environment), which share a common functional anatomy that includes frontal and medial temporal systems, have a function related to adaptive behavior: these are used adaptively to imagine perspectives and events beyond those which emerge from the immediate environment. Such an approach to the high-order cognitive functions (e.g., selfknowledge, autobiographical memory, and mentalizing) would clarify their functional significance and cognitive regulation processes. 


\section{REFERENCES}

Amodio, D. M., \& Frith, C. D. 2006. Meeting of minds: The medial frontal cortex and social cognition. Nature Reviews. Neuroscience, 7, 268-277.

Aron, A. R., Robbins, T. W., \& Poldrack, R. A. 2004. Inhibition and the right inferior frontal cortex. Trends in Cognitive Sciences, 8, 170-177.

Banks, S. J., Eddy, K. T., Angstadt, M., Nathan, P. J., \& Phan, K. L. 2007. Amygdala-frontal connectivity during emotion regulation. Social Cognitive and Affective Neuroscience, 2, 303-312.

Barbas, H., \& Pandya, D. N. 1989. Architecture and intrinsic connections of the prefrontal cortex in the rhesus monkey. Journal of Comparative Neurology, 286, 353-375.

Bechara, A., Damasio, A. R., Damasio, H., \& Anderson, S. W. 1994. Insensitivity to future consequences following damage to human prefrontal cortex. Cognition, 50, 7-15.

Bechara, A., Damasio, H., Damasio, A. R., \& Lee, G. P. 1999. Different contributions of the human amygdala and ventromedial prefrontal cortex to decision-making. The Journal of Neuroscience, 19, 5473-5481.

Bechara, A., Tranel, D., Damasio, H., \& Damasio, A. R. 1996. Failure to respond autonomically to anticipated future outcomes following damage to prefrontal cortex. Cerebral Cortex, 6, 215-225.

Botvinick, M. M., Braver, T. S., Barch, D. M., Carter, C. S., \& Cohen, J. D. 2001. Conflict monitoring and cognitive control. Psychological Review, 108, 624-652.

Brunet, E., Sarfati, Y., Hardy-Bayle, M. C., \& Decety, J. 2000. A PET investigation of the attribution of intentions with a nonverbal task. NeuroImage, 11, 157-166.

Buckner, R. L., \& Carroll, D. C. 2006. Self-projection and the brain. Trends in Cognitive Sciences, 11, 4957.

Calder, A. J., Lawrence, A. D., Keane, J., Scott, S. K., Owen, A. M., Christoffels, I. et al. 2002. Reading the mind from eye gaze. Neuropsychologia, 40, 1129-1138.

Castelli, F., Happe, F., Frith, U., \& Frith, C. 2000. Movement and mind: A functional imaging study of perception and interpretation of complex intentional movement patterns. NeuroImage, 12, 314-325.

Ciaramelli, E., Muccioli, M., Ladavas, E., \& di Pellegrino, G. 2007. Selective deficit in personal moral judgment following damage to ventromedial prefrontal cortex. Social Cognitive and Affective Neuroscience, 2, 84-92.

D’Argembeau, A., Ruby, P., Collette, F., Degueldre, C., Balteau, E., Luxen, A. et al. 2007. Distinct regions of the medial prefrontal cortex are associated with self-referential processing and perspective taking. Journal of Cognitive Neuroscience, 19, 935-944.

Durston, S., Davidson, M. C., Thomas, K. M., Worden, M. S., Tottenham, N., Martinez, A. et al. 2003. Parametric manipulation of conflict and response competition using rapid mixed-trial event-related fMRI. NeuroImage, 20, 2135-2141.

Egner, T., \& Hirsch, J. 2005a. The neural correlates and functional integration of cognitive control in a Stroop task. NeuroImage, 24, 539-547.

Egner, T., \& Hirsch, J. 2005b. Cognitive control mechanisms resolve conflict through cortical amplification of task-relevant information. Nature Neuroscience, 8, 1784-1790.

Elliott, R., Newman, J. L., Longe, O. A., \& Deakin, J. F. W. 2003. Differential response patterns in the striatum and orbitofrontal cortex to financial reward in humans: A parametric functional magnetic resonance imaging study. The Journal of Neuroscience, 23, 303-307.

Ernst, M., Nelson, E. E., McClure, E. B., Monk, C. S., Munson, S., Eshel, N. et al. 2004. Choice selection and reward anticipation: An fMRI study. Neuropsychologia, 42, 1585-1597.

Fletcher, P. C., Happe, F., Frith, U., Baker, S. C., Dolan, R. J., Frackowiak, R. S. J. et al. 1995. Other minds in the brain: A functional imaging study of "theory of mind" in story comprehension. Cognition, 57, 109-128.

Fossati, P., Hevenor, S. J., Graham, S. J., Grady, C., Keightley, M. L., Craik, F. et al. 2003. In search of the emotional self: An fMRI study using positive and negative emotional words. American Journal of Psychiatry, 160, 1938-1945.

Frith, C. D., \& Frith, U. 1999. Interacting minds: A biological basis. Science, 286, 1692-1695.

Frith, C. D., \& Frith, U. 2006. The neural basis of mentalizing. Neuron, 50, 531-534.

Fukui, H., Murai, T., Fukuyama, H., Hayashi, T., \& Hanakawa, T. 2005. Functional activity related to risk anticipation during performance of the Iowa Gambling Task. NeuroImage, 24, 253-259. 
Gallagher, H. L., \& Frith, C. D. 2003. Functional imaging of 'theory of mind'. Trends in Cognitive Sciences, 7, 77-83.

Gallagher, H. L., Happe, F., Brunswick, N., Fletcher, P. C., Frith, U., \& Frith, C. D. 2000. Reading the mind in cartoons and stories: An fMRI study of 'theory of mind' in verbal and nonverbal tasks. Neuropsychologia, 38, 11-21.

Goel, V., \& Dolan, R. J. 2003. Explaining modulation of reasoning by belief. Cognition, 87, B11-B22.

Goldman-Rakic, P. S. 1988. Topography of cognition: Parallel distributed networks in primate association cortex. Annual Review of Neuroscience, 11, 137-156.

Greene, J., \& Haidt, J. 2002. How (and where) does moral judgment work? Trends in Cognitive Sciences, 6 , $517-523$.

Greene, J. D., Nystrom, L. E., Engell, A. D., Darley, J. M., \& Cohen, J. D. 2004. The neural bases of cognitive conflict and control in moral judgment. Neuron, 44, 389-400.

Greene, J. D., Sommerville, R. B., Nystrom, L. E., Darley, J. M., \& Cohen, J. D. 2001. An fMRI investigation of emotional engagement in moral judgment. Science, 293, 2105-2108.

Gusnard, D. A., Akbudak, E., Shulman, G. L., \& Raichle, M. E. 2001. Medial prefrontal cortex and selfreferential mental activity: Relation to a default mode of brain function. Proceedings of the National Academy of Sciences of the USA, 98, 4259-4264.

Haensel, A., \& von Kaenel, R. 2008. The ventro-medial prefrontal cortex: A major link between the autonomic nervous system, regulation of emotion, and stress reactivity? BioPsychoSocial Medicine, 2, 21.

Han, S., Mao, L., Gu, X., Zhu, Y., Ge, J., \& Ma, Y. 2008. Neural consequences of religious belief on selfreferential processing. Social Neuroscience, 3, 1-15.

Harris, S., Sheth, S. A., \& Cohen, M. S. 2008. Functional neuroimaging of belief, disbelief, and uncertainty. Annals of Neurology, 63, 141-147.

Heatherton, T. F., Wyland, C. L., Macrae, C. N., Demos, K. E., Denny, B. T., \& Kelley, W. M. 2006. Medial prefrontal activity differentiates self from close others. Social Cognitive and Affective Neuroscience, $1,18-25$.

Heekeren, H. R., Wartenburger, I., Schmidt, H., Schwintowski, H. P., \& Villringer, A. 2003. An fMRI study of simple ethical decision-making. Neuroreport, 14, 1215-1219.

Hikosaka, K., \& Watanabe, M. 2000. Delay activity of orbital and lateral prefrontal neurons of the monkey varying with different rewards. Cerebral Cortex, 10, 263-271.

Hikosaka, K., \& Watanabe, M. 2004. Long- and short-range reward expectancy in the primate orbitofrontal cortex. The European Journal of Neuroscience, 19, 1046-1054.

Hoshi, E., Shima, K., \& Tanji, J. 1998. Task-dependent selectivity of movement-related neuronal activity in the primate prefrontal cortex. Journal of Neurophysiology, 80, 3392-3397.

Hoshi, E., Shima, K., \& Tanji, J. 2000. Neuronal activity in the primate prefrontal cortex in the process of motor selection based on two behavioral rules. Journal of Neurophysiology, 83, 2355-2373.

Hoshi, E., \& Tanji, J. 2004. Area-selective neuronal activity in the dorsolateral prefrontal cortex for information retrieval and action planning. Journal of Neurophysiology, 91, 2707-2722.

Hsu, M., Bhatt, M., Adolphs, R., Tranel, D., \& Camerer, C. F. 2005. Neural systems responding to degrees of uncertainty in human decision-making. Science, 310, 1680-1683.

Iacoboni, M., Lieberman, M. D., Knowlton, B. J., Molnar-Szakacs, I., Moritz, M., Throop, C. et al. 2004. Watching social interactions produces dorsomedial prefrontal and medial parietal BOLD fMRI signal increases compared to a resting baseline. NeuroImage, 21, 1167-1173.

Johnson, S. C., Baxter, L. C., Wilder, L. S., Pipe, J. G., Heiserman, J. E., \& Prigatano, G. P. 2002. Neural correlates of self-reflection. Brain, 125, 1808-1814.

Johnstone, T., van Reekum, C. M., Urry, H. L., Kalin, N. H., \& Davidson, R. J. 2007. Failure to regulate: counterproductive recruitment of top-down prefrontal-subcortical circuitry in major depression. The Journal of Neuroscience, 27, 8877-8884.

Kelley, W. M., Macrae, C. N., Wyland, C. L., Caglar, S., Inati, S., \& Heatherton, T. F. 2002. Finding the self? An event-related fMRI study. Journal of Cognitive Neuroscience, 14, 785-794.

Kerns, J. G., Cohen, J. D., MacDonald, A. W., Cho, R. Y., Stenger, V., \& Carter, C. S. 2004. Anterior cingulate conflict monitoring and adjustments in control. Science, 303, 1023-1026.

Kjaer, T. W., Nowak, M., \& Lou, H. C. 2002. Reflective self-awareness and conscious states: PET evidence 
for a common midline parietofrontal core. NeuroImage, 17, 1080-1086.

Knutson, B., Taylor, J., Kaufman, M., Peterson, R., \& Glover, G. 2005. Distributed neural representation of expected value. The Journal of Neuroscience, 25, 4806-4812.

Konishi, S., Nakajima, K., Uchida, I., Kikyo, H., Kameyama, M., \& Miyashita, Y. 1999. Common inhibitory mechanism in human inferior prefrontal cortex revealed by event-related functional MRI. Brain, 122, 981-991.

Krueger, F., Moll, J., Zahn, R., Heinecke, A., \& Grafman, J. 2007. Event frequency modulates the processing of daily life activities in human medial prefrontal cortex. Cerebral Cortex, 17, 2346-2353.

Lane, R. D., Fink, G. R., Chau, P. M. L., \& Dolan, R. J. 1997. Neural activation during selective attention to subjective emotional responses. Neuroreport, 8, 3969-3972.

Lieberman, M. D., \& Eisenberger, N. I. 2005. Conflict and habit: A social cognitive neuroscience approach to the self. In A. Tesser, J. V. Wood, \& D. A. Stapel (Eds.), On building, defending and regulating the self: A psychological perspective (pp. 77-102). New York: Psychology Press.

Lieberman, M. D., Jarcho, J. M., \& Satpute, A. B. 2004. Evidence-based and intuition-based self-knowledge: An fMRI study. Journal of Personality and Social Psychology, 87, 421-435.

Lotze, M., Veit, R., Anders, S., \& Birbaumer, N. 2007. Evidence for a different role of the ventral and dorsal medial prefrontal cortex for social reactive aggression: An interactive fMRI study. NeuroImage, 34, 470-478.

Luks, T. L., Simpson, G. V., Feiwell, R. J., \& Miller, W. L. 2002. Evidence for anterior cingulate cortex involvement in monitoring preparatory attentional set. Neurolmage, 17, 792-802.

MacDonald, A. W. 3rd, Cohen, J. D., Stenger, V. A., \& Carter, C. S. 2000. Dissociating the role of the dorsolateral prefrontal and anterior cingulate cortex in cognitive control. Science, 288, 1835-1838.

MacLeod, C. M. 1991. Half a century of research on the Stroop effect: An integrative review. Psychological Bulletin, 109, 163-203.

Matsumoto, K., Suzuki, W., \& Tanaka, K. 2003. Neuronal correlates of goal-based motor selection in the prefrontal cortex. Science, 301, 229-232.

Matsumoto, K., \& Tanaka, K. 2004a. Conflict and cognitive control. Science, 303, 969-970.

Matsumoto, K., \& Tanaka, K. 2004b. The role of the medial prefrontal cortex in achieving goals. Current Opinion in Neurobiology, 14, 178-185.

Milham, M. P., Banich, M. T., \& Barad, V. 2003. Competition for priority in processing increases prefrontal cortex's involvement in top-down control: An event-related fMRI study of the stroop task. Cognitive Brain Research, 17, 212-222.

Mitchell, J. P., Banaji, M. R., \& Macrae, C. N. 2005. General and specific contributions of the medial prefrontal cortex to knowledge about mental states. NeuroImage, 28, 757-762.

Mitchell, J. P., Macrae, C. N., \& Banaji, M. R. 2006. Dissociable medial prefrontal contributions to judgments of similar and dissimilar others. Neuron, 50, 655-663.

Moll, J., de Oliveira-Souza, R., Bramati, I. E., \& Grafman, J. 2002. Functional networks in emotional moral and nonmoral social judgments. NeuroImage, 16, 696-703.

Moll, J., de Oliveira-Souza, R., Eslinger, P. J., Bramati, I. E., Mourao-Miranda, J., Andreiuolo, P. A. et al. 2002. The neural correlates of moral sensitivity: A functional magnetic resonance imaging investigation of basic and moral emotions. The Journal of Neuroscience, 22, 2730-2736.

Nakao, T., Miyatani, M., Nakao, M., Takezawa, T., Maruishi, M., Muranaka, H. et al. 2009. Does the medial prefrontal cortex activity during self-knowledge reference reflect uniqueness of self-knowledge? Japanese Psychological Research, 51, 69-84.

Nakao, T., Takezawa, T., \& Miyatani, M. 2006. Function of the medial prefrontal cortex: Benchmark hypothesis. Japanese Psychological Review, 49, 592-612.

Nakao, T., Takezawa, T., Shiraishi, M., \& Miyatani, M. in press. Activation of self-knowledge reduces conflict during occupational choice: An ERP study. International Journal of Neuroscience.

Nomura, M. 2004. Neural network for effectively processing the emotions expressed by others. Japanese Psychological Review, 47, 71-88.

Northoff, G., \& Bermpohl, F. 2004. Cortical midline structures and the self. Trends in Cognitive Sciences, 8 , $102-107$.

Northoff, G., Heinzel, A., de Greck, M., Bermpohl, F., Dobrowolny, H., \& Panksepp, J. 2006. Self-referential processing in our brain-A meta-analysis of imaging studies on the self. NeuroImage, 31, 440-457. 
Ochsner, K. N., Beer, J. S., Robertson, E. R., Cooper, J. C., Gabrieli, J. D. E., Kihlstrom, J. F. et al. 2005. The neural correlates of direct and reflected self-knowledge. NeuroImage, 28, 797-814.

Ochsner, K. N., Bunge, S. A., Gross, J. J., \& Gabrieli, J. D. E. 2002. Rethinking feelings: An fMRI study of the cognitive regulation of emotion. Journal of Cognitive Neuroscience, 14, 1215-1229.

Ochsner, K. N., \& Gross, J. J. 2008. Cognitive emotion regulation: Insights from social cognitive and affective neuroscience. Current Directions in Psychological Science, 17, 153-158.

Ochsner, K. N., Knierim, K., Ludlow, D. H., Hanelin, J., Ramachandran, T., Glover, G. et al. 2004. Reflecting upon feelings: An fMRI study of neural systems supporting the attribution of emotion to self and other. Journal of Cognitive Neuroscience, 16, 1746-1772.

Ochsner, K. N., Ray, R. D., Cooper, J. C., Robertson, E. R., Chopra, S., Gabrieli, J. D. E. et al. 2004. For better or for worse: Neural systems supporting the cognitive down- and up-regulation of negative emotion. NeuroImage, 23, 483-499.

O’Doherty, J., Critchley, H., Deichmann, R., \& Dolan, R. J. 2003. Dissociating valence of outcome from behavioral control in human orbital and ventral prefrontal cortices. The Journal of Neuroscience, 23, 7931-7939.

O’Doherty, J., Kringelbach, M. L., Rolls, E. T., Hornak, J., \& Andrews, C. 2001. Abstract reward and punishment representations in the human orbitofrontal cortex. Nature Neuroscience, 4, 95-102.

Ongur, D., \& Price, J. L. 2000. The organization of networks within the orbital and medial prefrontal cortex of rats, monkeys and humans. Cerebral Cortex, 10, 206-219.

Paulus, M. P., \& Frank, L. R. 2003. Ventromedial prefrontal cortex activation is critical for preference judgments. Neuroreport, 14, 1311-1315.

Petrides, M. 1995. Impairments on nonspatial self-ordered and externally ordered working memory tasks after lesions of the mid-dorsal part of the lateral frontal cortex in the monkey. Journal of Neuroscience, 15, 359-375.

Petrides, M., \& Pandya, D. N. 2007. Efferent association pathways from the rostral prefrontal cortex in the macaque monkey. The Journal of Neuroscience, 27, 11573-11586.

Price, J. L. 2007. Definition of the orbital cortex in relation to specific connections with limbic and visceral structures, and other cortical regions. Annals of the New York Academy of Sciences, 1121, 54-71.

Ridderinkhof, K. R., Ullsperger, M., Crone, E. A., \& Nieuwenhuis, S. 2004. The role of the medial frontal cortex in cognitive control. Science, 306, 443-447.

Ridderinkhof, K. R., van den Wildenberg, W. P., Segalowitz, S. J., \& Carter, C. S. 2004. Neurocognitive mechanisms of cognitive control: The role of prefrontal cortex in action selection, response inhibition, performance monitoring, and reward-based learning. Brain and Cognition, 56, 129-140.

Rogers, R. D., Ramnani, N., Mackay, C., Wilson, J. L., Jezzard, P., Carter, C. S. et al. 2004. Distinct portions of anterior cingulate cortex and medial prefrontal cortex are activated by reward processing in separable phases of decision-making cognition. Biological Psychiatry, 55, 594-602.

Rolls, E. T. 2000. The orbitofrontal cortex and reward. Cerebral Cortex, 10, 284-294.

Rolls, E. T. 2004. The functions of the orbitofrontal cortex. Brain and Cognition, 55, 11-29.

Rolls, E. T., Hornak, J., Wade, D., \& McGrath, J. 1994. Emotion-related learning in patients with social and emotional changes associated with frontal lobe damage. Journal of Neurology, Neurosurgery, and Psychiatry, 57, 1518-1524.

Sato, A., \& Ohira, H. 2001. Error, conflict and the anterior cingulate cortex: Dissociating executive functions of the prefrontal cortex. Japanese Psychological Review, 44, 398-421.

Saxe, R., Moran, J. M., Scholz, J., \& Gabrieli, J. 2006. Overlapping and non-overlapping brain regions for theory of mind and self-reflection in individual subjects. Social Cognitive and Affective Neuroscience, 1, 229-234.

Schmitz, T. W., Rowley, H. A., Kawahara, T. N., \& Johnson, S. C. 2006. Neural correlates of self-evaluative accuracy after traumatic brain injury. Neuropsychologia, 44, 762-773.

Seger, C. A., Stone, M., \& Keenan, J. P. 2004. Cortical activations during judgments about the self and an other person. Neuropsychologia, 42, 1168-1177.

Semendeferi, K., Armstrong, E., Schleicher, A., Zilles, K., \& Van Hoesen, G. W. 2001. Prefrontal cortex in humans and apes: A comparative study of area 10. American Journal of Physical Anthropology, 114, 224-241.

Simon-Thomas, E. R., \& Knight, R. T. 2005. Affective and cognitive modulation of performance monitoring: 
Behavioral and ERP evidence. Cognitive, Affective, \& Behavioral Neuroscience, 5, 362-372.

Small, D. M., Zatorre, R. J., Dagher, A., Evans, A. C., \& Jones-Gotman, M. 2001. Changes in brain activity related to eating chocolate: From pleasure to aversion. Brain, 124, 1720-1733.

Stroop, J. R. 1935. Studies of interference in serial verbal reactions. Journal of Experimental Psychology, 18, 643-662.

Takahashi, H., Yahata, N., Koeda, M., Matsuda, T., Asai, K., \& Okubo, Y. 2004. Brain activation associated with evaluative processes of guilt and embarrassment: An fMRI study. NeuroImage, 23, 967-974.

Tanji, J., \& Hoshi, E. 2008. Role of the lateral prefrontal cortex in executive behavioral control. Physiological Reviews, 88, 37-57.

Urry, H. L., van Reekum, C. M., Johnstone, T., Kalin, N. H., Thurow, M. E., Schaefer, H. S. et al. 2006. Amygdala and ventromedial prefrontal cortex are inversely coupled during regulation of negative affect and predict the diurnal pattern of cortisol secretion among older adults. The Journal of Neuroscience, 26, 4415-4425.

Vanderwal, T., Hunyadi, E., Grupe, D. W., Connors, C. M., \& Schultz, R. T. 2008. Self, mother and abstract other: An fMRI study of reflective social processing. NeuroImage, 41, 1437-1446.

Vogeley, K., Bussfeld, P., Newen, A., Herrmann, S., Happe, F., Falkai, P. et al. 2001. Mind reading: Neural mechanisms of theory of mind and self-perspective. NeuroImage, 14, 170-181.

Volz, K. G., Schubotz, R. I., \& von Cramon, D. Y. 2003. Predicting events of varying probability: Uncertainty investigated by fMRI. NeuroImage, 19, 271-280.

Volz, K. G., Schubotz, R. I., \& von Cramon, D. Y. 2004. Why am I unsure? Internal and external attributions of uncertainty dissociated by fMRI. NeuroImage, 21, 848-857.

Xue, G., Lu, Z., Levin, I. P., Weller, J. A., Li, X., \& Bechara, A. in press. Functional dissociations of risk and reward processing in the medial prefrontal cortex. Cerebral Cortex.

Young, L., \& Koenigs, M. 2007. Investigating emotion in moral cognition: A review of evidence from functional neuroimaging and neuropsychology. British Medical Bulletin, 84, 69-79.

Zysset, S., Huber, O., Ferstl, E., \& von Cramon, D. Y. 2002. The anterior frontomedian cortex and evaluative judgment: An fMRI study. NeuroImage, 15, 983-991.

Zysset, S., Huber, O., Samson, A., Ferstl, E. C., \& von Cramon, D. Y. 2003. Functional specialization within the anterior medial prefrontal cortex: A functional magnetic resonance imaging study with human subjects. Neuroscience Letters, 335,183-186. 